\title{
Necessity of Antiaggregation and Anticoagulation and Its Prognostic Impact: A Cardiologist's View
}

\author{
Ulrich Hink $^{a}$ Thomas Voigtländer ${ }^{b}$ \\ ${ }^{a}$ Klinik für Innere Medizin 3 - Kardiologie, Angiologie und Internistische Intensivmedizin, Klinikum Frankfurt Höchst, \\ Frankfurt, Germany; ${ }^{\mathrm{b} C a r d i o a n g i o l o g i s c h e s ~ C e n t r u m ~ B e t h a n i e n, ~ A G A P L E S I O N-B e t h a n i e n-K r a n k e n h a u s, ~ F r a n k f u r t, ~}$ \\ Germany
}

\section{Keywords}

Antiaggregation · Anticoagulation - Antiplatelet therapy · Bleeding $\cdot$ Cardiology $\cdot$ Cardiovascular disease ic substances. Conclusions: Anticoagulation and antiaggregation are of major prognostic relevance in cardiovascular diseases. However, the inherent bleeding risk has to be considered.

() 2020 S. Karger AG, Basel

\begin{abstract}
Background: In modern cardiology, anticoagulation and antiaggregation are key components of current treatment strategies. However, in patients treated with anticoagulation and antiplatelet substances, bleeding is a major risk. Findings: In all major cardiovascular diseases, a multitude of studies have shown a positive impact of antithrombotic treatment on cardiovascular death. In patients with higher bleeding risks, recent studies showed the safety of reducing the period of dual antiplatelet therapy (DAPT), i.e., after percutaneous coronary intervention. In patients with coronary artery disease and atrial fibrillation (AF), triple therapy including DAPT and anticoagulation is associated with very high bleeding risks. However, recently published data showed the safety of direct oral anticoagulants (DOACs) and P2Y12 inhibitors only compared to vitamin $\mathrm{K}$ antagonist (VKA) and DAPT. Anticoagulation in nonvalvular AF reduces major cerebrovascular ischemic events. However, the inherent cerebrovascular bleeding risk is an important concern of this treatment. With the advent of DOACs, this risk could be reduced compared to VKA. Furthermore, anticoagulation and antiaggregation are crucial after treatment of valve disease, both after surgical and interventional procedures. Even in heart failure, new data show benefits using antithrombot-
\end{abstract}

\section{Introduction}

The more recent antithrombotic and anticoagulatory substances are probably the most important game changers in the medical treatment of cardiovascular diseases. For example, the entire field of interventional cardiology is hard to imagine without the P2Y12 inhibitors (clopidogrel, prasugrel, ticagrelor). The direct oral anticoagulants (DOACs) are generally available and treatment of atrial fibrillation (AF) is possible for even larger patient collectives than in the past decades. Up to $12 \%$ of patients with coronary artery disease (CAD) suffer from AF. Many of these patients need treatment combining both antiaggregation and anticoagulation. The main side effect of these new substances consists of bleeding. Among others, gastrointestinal bleeding is one of the most important severe conditions if patients are treated with these substances. In some cases, this has a life-threatening impact, severe bleeding being associated with a $10 \%$ mortality [1]. Therefore, the positive prognostic impact of antiaggregation and anticoagulation must be counterbalanced against its negative influence on prognosis. 


\section{Bleeding Risk}

In 2011, the Bleeding Academic Research Consortium (BARC) published standardized bleeding definitions for cardiovascular clinical trials [2]. Whereas types 1 and 2 describe minor bleeding, high bleeding risk is defined as a BARC type 3 or 5 bleeding risk (Table 1 ) of $\geq 4 \%$ at 1 year or a risk of intracranial hemorrhage of $\geq 1 \%$ at 1 year. The bleeding risk for the individual patient can be assessed using scores which focus on antiplatelet (PRECISE-DAPT) and antiaggregation (HAS-BLED) treatment. A more recent definition of minor and major bleeding risk in patients undergoing percutaneous coronary intervention (PCI) is shown in Table 2 [3].

Table 1. BARC types 3-5

Type 3a Any transfusion without overt bleeding Overt bleeding plus hemoglobin drop $>3$ and $<5 \mathrm{~g} / \mathrm{dL}$

Type $3 \mathrm{~b}$ Overt bleeding $>5 \mathrm{~g} / \mathrm{dL}$ Bleeding requiring surgical intervention and/or requiring intravenous vasoactive substances

Type 3c Intracranial hemorrhage, intraocular bleed compromising vision

Type 4 Coronary artery bypass graft-related bleeding

Type 5 Fatal bleeding

BARC, Bleeding Academic Research Consortium.

\section{Coronary Artery Disease}

Cardiovascular disease is the most common cause of death in Europe, accounting for 4 million deaths each year. This corresponds to $45 \%$ of all deaths. Coronary heart disease and cerebrovascular disease are the most common causes of cardiovascular death, and coronary heart disease accounts for 1.8 million deaths, corresponding to 19 and $20 \%$ of all deaths in men and women, respectively. Cardiovascular disease has declined rapidly in almost all Western European countries, with a reduction of up to $30-50 \%$ in the last 10 years $[4,5]$. For decades, the understanding of CAD has focused on acute coronary syndrome (ACS) and stable CAD (SCAD). In 2019, in a new guideline, the term chronic coronary syndrome (CCS) was introduced in order to cover the entire history of patients suffering from CAD [6]. Optimal medical treatment and revascularization play a crucial role in reducing the number of negative events during the individual history of the single patient. In this context, the role of antiaggregation and anticoagulation serving as prognostic tools should be emphasized.

\section{Acute Coronary Syndrome}

The total number of patients suffering from myocardial infarction (STEMI and NSTEMI) decreased over the last decade and a shift from STEMI to NSTEMI occurred. The underlying pathophysiology of ACS consisting of plaque rupture and the consecutive adhesion of thrombocytes is the reason why antiaggregation is a key concept of treatment. The widely used substances for antiaggrega-

Table 2. Minor and major criteria for high bleeding risk at the time of percutaneous coronary intervention

\begin{tabular}{ll}
\hline Minor & Major \\
\hline Age $<75$ years & Anticipated use of long-term anticoagulation \\
\hline eGFR $30-59 \mathrm{~mL} / \mathrm{min}$ & $\mathrm{eGFR}<30 \mathrm{~mL} / \mathrm{min}$ \\
\hline Hemoglobin $11-12.9 \mathrm{~g} / \mathrm{dL}(\mathrm{men})$ or $11-11.9 \mathrm{~g} / \mathrm{dL}($ women) & Hemoglobin $<11.0 \mathrm{~g} / \mathrm{dL}$ \\
\hline $\begin{array}{l}\text { Spontaneous bleeding in the last } 12 \text { months requiring } \\
\text { hospitalization or transfusion }\end{array}$ & $\begin{array}{l}\text { Spontaneous bleeding requiring hospitalization or transfusion } \\
\text { in the past } 6 \text { months or at any time, if recurrent }\end{array}$ \\
\hline Long-term use of oral NSAIDs or steroids & Thrombocytopenia $<100,000 / \mu \mathrm{L}$ \\
\hline Ischemic stroke at any time & Chronic bleeding diathesis \\
\hline Active malignancy & Liver cirrhosis with portal hypertension \\
\hline
\end{tabular}

Previous spontaneous (at any time) or traumatic intracranial

hemorrhage (in the last 12 months), stroke within the last 6 months

Nondeferrable major surgery on DAPT

Recent major trauma or major surgery within 30 days before percutaneous coronary intervention

DAPT, dual antiplatelet therapy; NSAIDs, nonsteroidal anti-inflammatory drugs. 
tion are ASA and P2Y12 inhibitors. ASA blocks the thromboxane-mediated thrombocyte aggregation by irreversible inhibition of cyclooxygenase, while clopidogrel, prasugrel, and ticagrelor inhibit ADP-mediated platelet activation by blocking the P2Y12 receptor. Both pathways are essential targets for treatment of ACS patients. In most situations concerning ACS, dual antiplatelet therapy (DAPT) is proven to be of prognostic relevance. However, DAPT plays its most prominent role in the treatment after PCI and concomitant stent implantation in patients suffering from acute or chronic coronary syndromes [7]. There are different scenarios for the role of antiplatelet treatment in patients with ACS:

ACS (STEMI, NSTEMI, Unstable Angina) without PCI. Nowadays, noninvasive treatment in this patient group is very rare. Invasive treatment shows significant prognostic benefit in these patients and is a class I A recommendation in all guidelines. However, in special conditions (e.g., multimorbidity, CAD without options for revascularization) a medical-only treatment is necessary. Even in patients without invasive treatment, DAPT is the accepted standard of medical treatment. The rational for these strategies derives from the CURE study (2001) comparing ASA alone versus ASA and clopidogrel for 9-12 months. The first primary outcome - a composite of death from cardiovascular causes, nonfatal myocardial infarction, or stroke - occurred in $9.3 \%$ of patients in the clopidogrel group and $11.4 \%$ of patients in the placebo group $(\mathrm{RR}=0.80,95 \% \mathrm{CI} 0.72-0.90, p<0.001)$ [8]. The PLATO study investigated different P2Y12 inhibitors and showed the superiority of ticagrelor compared to clopidogrel in these ACS patients. By the end of follow-up the incidence of the primary endpoint (cardiovascular death, myocardial infarction, and stroke) was lower with ticagrelor than with clopidogrel (12.0 vs. 14.3\%; HR (95\% CI) $0.85,0.73-1.00, p=0.04)$. Overall mortality was also lower (6.1 vs. $8.2 \%$; HR (95\% CI) $0.75,0.61-0.93, p=$ $0.01)$. The incidence of total major bleeding (11.9 vs. $10.3 \% ; p=0.08)$ showed no difference $[9,10]$. Stent occlusion is no major concern in these patients. If patients in this group have a high bleeding risk, the DAPT guideline [5] recommends DAPT only for 1 month. The assessment of bleeding risk can easily be calculated by using the PRECISE-DAPT score (parameters: hemoglobin, age, white blood cells, creatinine clearance [GFR], prior bleeding). This score was developed to predict the risk of bleeding in patients treated with DAPT (i.e., aspirin plus a P2Y12 inhibitor) from a collaborative dataset including data from eight randomized clinical trials. Bleeding events were defined according to the Thrombosis in Myocardial Infarction bleeding definition. A value $>25$ indicates increased bleeding risk [11].

ACS (STEMI, NSTEMI, Unstable Angina) with PCI. Due to the prognostic benefits in patients with ACS, acute
PCI is performed in the majority of cases even in the elderly [12]. According to the European Society of Cardiology (ESC) guidelines, DAPT is recommended for 12 months. The rational for DAPT in ACS patients treated with PCI includes the benefit of DAPT independently from PCI and the necessity of DAPT after stenting for preventing acute stent thrombosis. The preferred P2Y12 inhibitors are prasugrel and ticagrelor. These drugs have a more rapid onset of action, greater potency, and are superior to clopidogrel in clinical outcomes $[7,8]$. Prasugrel is contraindicated in patients with previous stroke/transient ischemic attack, and its use is generally not recommended in patients aged $>75$ years or in patients with low body weight $(<60 \mathrm{~kg})$ as it was not associated with net clinical benefit in these subsets. In case prasugrel is used in these patients, a reduced dose ( $5 \mathrm{mg}$ ) is recommended. Recently, the ISAR-REACT study compared prasugrel with ticagrelor in patients with ACS. The primary endpoint was the composite of death, myocardial infarction, or stroke at 1 year. A primary endpoint event occurred in 184 of 2,012 patients $(9.3 \%)$ in the ticagrelor group and in 137 of 2,006 patients $(6.9 \%)$ in the prasugrel group $(\mathrm{HR}=1.36,95 \%$ CI $1.09-1.70, p=0.006)$. Major bleeding (as defined by the BARC scale) was observed in $5.4 \%$ of patients in the ticagrelor group and in $4.8 \%$ of patients in the prasugrel group $(\mathrm{HR}=1.12,95 \% \mathrm{CI} 0.83-1.51, p=$ $0.46)$ [13]. In summary, the use of DAPT in patients with ACS and PCI has a major prognostic impact and is responsible for the decreasing mortality of patients with ACS. Nevertheless, this prognostic advantage must be seen in the light of bleeding complications. Therefore, in patients with high bleeding risk, a "stepdown strategy" is recommended. In these patients ticagrelor or prasugrel can be substituted by clopidogrel. Another stepdown strategy consists of shortening the DAPT period to 6 months. Very recent data showed the safety of DAPT for only 3 months in patients who were at high risk for bleeding or an ischemic event and had undergone PCI. In this study ASA and ticagrelor was given for only 3 months followed by ticagrelor alone. Compared to patients with DAPT for 12 months (ASA and ticagrelor), the bleeding risk was significantly reduced and there was no increase in ischemic events [14]. Generally, during DAPT treatment a proton pump inhibitor is recommended.

\section{Chronic Coronary Syndrome}

Definition. Recently the individual history of patients suffering from CAD was summarized and the terminology has changed to CCS. This includes the preclinical period, symptomatic but SCAD, and events with ACS (Fig. 1).

Primary Prevention. Antiplatelet treatment in patients without clinically relevant events (e.g., myocardial infarction, PCI, coronary artery bypass graft, etc.) has recently 
Fig. 1. CCS: adapted from Townsend et al. [4]. ACS, acute coronary syndrome; CCS, chronic coronary syndrome.

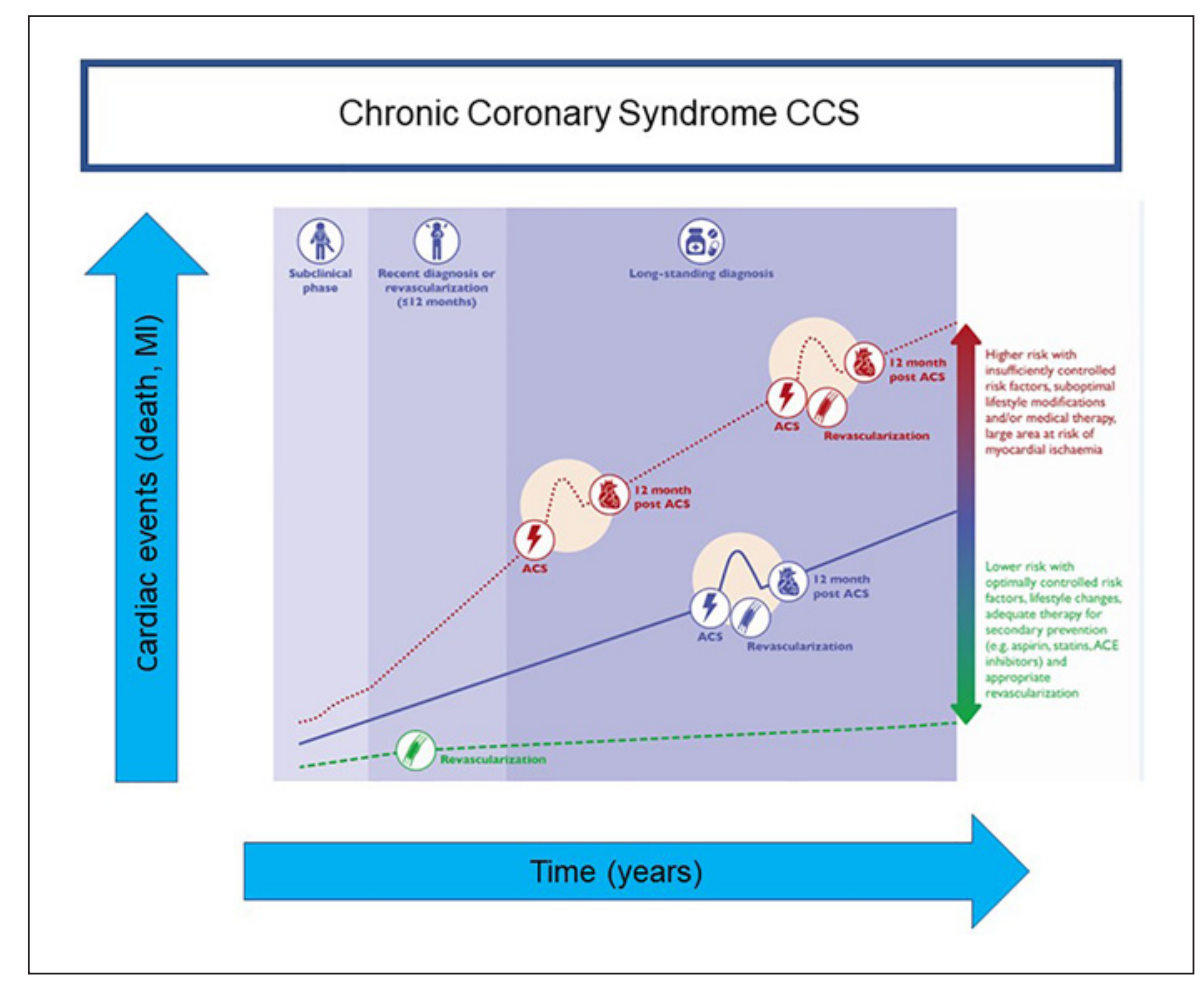

shown not to be effective in terms of reducing cardiac events [15]. Only in very-high-risk patients or in certain circumstances with, e.g., CT imaging of highly vulnerable plaque ASA treatment could be indicated.

Chronic Coronary Syndrome - SCAD. In patients with SCAD, the indication for interventional treatment is based on symptoms and degree of the ischemic area of the left ventricle. An ischemic area of $>10 \%$ of the myocardium of the left ventricle is intended to be prognostically relevant. Moreover, the CCS guideline recommends PCI in relevant stenosis of the left main stem or proximal stenosis in major coronary vessels [4]. However, very recent data (ISCHEMIA trial) comparing optimal medical treatment with revascularization showed significantly better symptom release, but no significant prognostic benefit of PCI in SCAD within a follow-up period of 3.2 years [16]. The ESC guidelines recommend drug-eluting stents as the standard care. Due to the superior data in terms of restenosis there is no longer any indication for bare metal stents. Generally, after drug-eluting stent implantation, 6 months of DAPT with ASA and clopidogrel are recommended. DAPT treatment is necessary in order to prevent acute thrombotic stent occlusion. Using modern thirdgeneration stents and thin struts of about $60 \mu \mathrm{m}$ stent, the thrombosis rate is as low as $0.2 \%$ per year. However, acute stent occlusion is associated with high morbidity and mortality. Recently, data reported mortality rates up to $47 \%$ [17]. DAPT $>6$ months is not recommended in patients with CCS. In secondary prevention, i.e., in patients with established SCAD, ASA results in a 19\% lower risk of major adverse cardiovascular events and a 9\% lower risk of cardiovascular death than placebo [18]. In these patients there is no general indication for prasugrel or ticagrelor. However, some data favor a more aggressive secondary prevention. In patients after myocardial infarction 1-3 years earlier, ASA and ticagrelor $60 \mathrm{mg}$ b.i.d. significantly reduced the risk of cardiovascular death, myocardial infarction, or stroke. However, the rates of Thrombosis in Myocardial Infarction major bleeding were higher with ticagrelor ( 2.30 vs. $1.06 \%$ [placebo], $p<$ 0.001 ) [19]. Another strategy of aggressive secondary prevention consists in adding rivaroxaban 2.5 b.i.d. to ASA in patients with CCS [20]. The primary outcome occurred in fewer patients in the rivaroxaban plus aspirin group than in the aspirin-alone group (4.1 vs. $5.4 \%$; $\mathrm{HR}=0.76$, $95 \%$ CI $0.66-0.86, p<0.001$ ), but major bleeding events occurred in more patients in the rivaroxaban plus aspirin group (3.1 vs. $1.9 \%$; $\mathrm{HR}=1.70,95 \%$ CI $1.40-2.05, p<$ $0.001)$.

PCI in Patients with SCAD and High Bleeding Risk. Due to the low rate of stent thrombosis using current stent technology, studies investigating the possibility of a shorter DAPT period in order to reduce bleeding events were performed. According to the current data and the ESC guideline [4], in patients with high bleeding risk the period of DAPT can safely reduced to 3 months. Nevertheless, optimal DAPT duration after drug-eluting stent implantation differs according to clinical presentation. In 
a meta-analysis, despite the fact that most enrolled ACS patients were at rather low risk, 3-month DAPT was associated with increased ischemic risk, whereas it appeared to be safe in patients with SCAD [21]. Moreover, in patients after PCI with SCAD, the safety of further shortening of DAPT were studied. Very recent data show no increased stent thrombosis rate with continuation of clopidogrel only after 1 month of DAPT [22]. Another study documented that within 12 months using contemporary drug-eluting stents, no major safety issues occurred after DAPT for 1 month followed by monotherapy with ASA or clopidogrel [23]. Prolonged DAPT increases bleeding regardless of clinical presentation. The balance between bleeding risk and the risk of stent occlusion should be analyzed in each individual patient. However, newer data justify shorter DAPT in patients with higher bleeding risks. Additionally, comparable to PCI in patients with ACS, proton pump inhibitor should be given routinely in order to further reduce bleeding complications.

\section{CAD and Anticoagulation}

The combination of antiaggregation and anticoagulation has become relevant in patients with CCS and AF, mostly nonvalvular AF. Recently, Morita et al. [24] showed an increase in patients suffering from CCS and AF. In a large database, the authors observed between 2005 and 2014 a steady increase in the incidence of AF and PCI from 8.6 to $12.0 \%$. There was a marked increase in AF prevalence among those aged $\geq 65$ years and those undergoing elective PCIs. AF was independently associated with higher in-hospital mortality and higher rates of transient ischemic attack/stroke and bleeding complications. In these patients, the need for prevention of stent thrombosis and for prevention of atrial embolism because of AF has led to the concept of triple therapy (DAPT + anticoagulant). Unfortunately, this is associated with very high bleeding rates. Firstly, the WOEST study showed that anticoagulation with vitamin $\mathrm{K}$ antagonist (VKA) combined with antiaggregation, performed only by clopidogrel (and omitting ASA) known as dual therapy, significantly reduced bleeding rates without an increase in stent thrombosis rate. The primary outcome of any bleeding event was significantly decreased in the dual therapy group (19.4\%) compared to the triple therapy group (44.4\%) at 1-year follow-up. This outcome was consistent across all subgroups, including ACS patients. Although the WOEST study was not powered to assess efficacy outcomes, dual therapy significantly reduced the composite endpoint of death, stroke, myocardial infarction, stent thrombosis, and target vessel revascularization compared to the triple therapy group (11.1 and $17.6 \%$, respectively) [25].

$C A D$ and Direct Oral Anticoagulation. Due to positive results when treating AF using DOACs instead of VKA, this concept was adapted early even for patients with $\mathrm{AF}$ and CAD treated with PCI. Now for all DOAC substances that are approved for clinical use, randomized data are published.

PIONEER-AF Study (Rivaroxaban) [26]. In this first study investigating dual therapy with a DOAC, rivaroxaban $15 \mathrm{mg}$ and a P2Y12 inhibitor were compared with VKA and DAPT. Bleeding was significantly reduced with dual therapy ( 16.8 vs. $26.7 \%$; $p<0.0001,95 \%$ CI $0.28-$ 0.58 ) without differences in safety (cardiovascular death, myocardial infarction, or stroke; 6.5 vs. $6.0 \%$; $p=n s$ ). However, in the current ESC guidelines the use of rivaroxaban $15 \mathrm{mg}$ only has a II b recommendation. Due to the better prevention of cardioembolic events, the guidelines favor $20 \mathrm{mg}$ rivaroxaban as part of the dual therapy.

Re-DUAL PCI Study (Dabigatran) [27]. This study compared dabigatran $(2 \times 150 \mathrm{mg}$ and $2 \times 110 \mathrm{mg})$ with P2Y12 inhibitor to triple therapy with DAPT and VKA; bleeding occurred significantly less in both dabigatran groups compared to the triple therapy group (20.2 vs. $24.2 \%$; $95 \%$ CI $0.58-0.88, p=0.002$ ). Safety issues (myocardial infarction, stroke, systemic embolism, death, or unplanned revascularization) were statistically not different between groups ( 11.8 vs. $12.8 \%, p=0.44$ ), but numerically stent thrombosis occurred in $0.9 \%$ using dabigatran $150 \mathrm{mg}$ b.i.d. compared to $1.5 \%$ using $110 \mathrm{mg}$ b.i.d.

AUGUSTUS Trial (Apixaban) [28]. In this trial, apixaban $2 \times 5 \mathrm{mg}$ and P2Y12 inhibitor alone or with ASA (triple therapy) was compared with VKA and P2Y12 inhibitor alone or with ASA in a two-by-two factorial trial design. Major or clinically relevant nonmajor bleeding was noted in $10.5 \%$ of the patients receiving apixaban, as compared with $14.7 \%$ of those receiving VKA $(\mathrm{HR}=0.69$, $95 \%$ CI $0.58-0.81, p<0.001$ for both noninferiority and superiority), and in $16.1 \%$ of the patients receiving aspirin, as compared with $9.0 \%$ of those receiving placebo $(\mathrm{HR}=1.89,95 \%$ CI $1.59-2.24, p<0.001)$. Patients in the apixaban group had a similar incidence of ischemic events. Patients in the aspirin group had an incidence of death or hospitalization and of ischemic events that was similar to that in the placebo group. In conclusion, apixaban $2 \times 5 \mathrm{mg}$ and P2Y12 inhibitor without ASA (dual therapy) showed the best results, with less bleeding and no increased safety concerns compared to triple therapy.

ENTRUST-AF (Edoxaban) [29]. The edoxaban regimen $(60 \mathrm{mg}$ ) and P2Y12 inhibitor was noninferior to standard therapy for the composite primary endpoint of major bleeding or clinically relevant nonmajor bleeding. With 128 (17.0\%) events in the edoxaban group and 152 (20.1\%) events in the VKA group, there was a trend towards less bleeding, but statistical superiority was not met. In terms of safety no differences occurred. Interestingly, in regard to reduction of bleeding events, DOAC treatment showed no superiority compared to triple ther- 
Fig. 2. Efficacy and safety outcomes in pivotal phase 3 randomized trials of patients with AF (adapted from Pisters et al. [34]). $\mathrm{AF}$, atrial fibrillation; NOAC, novel oral anticoagulant.

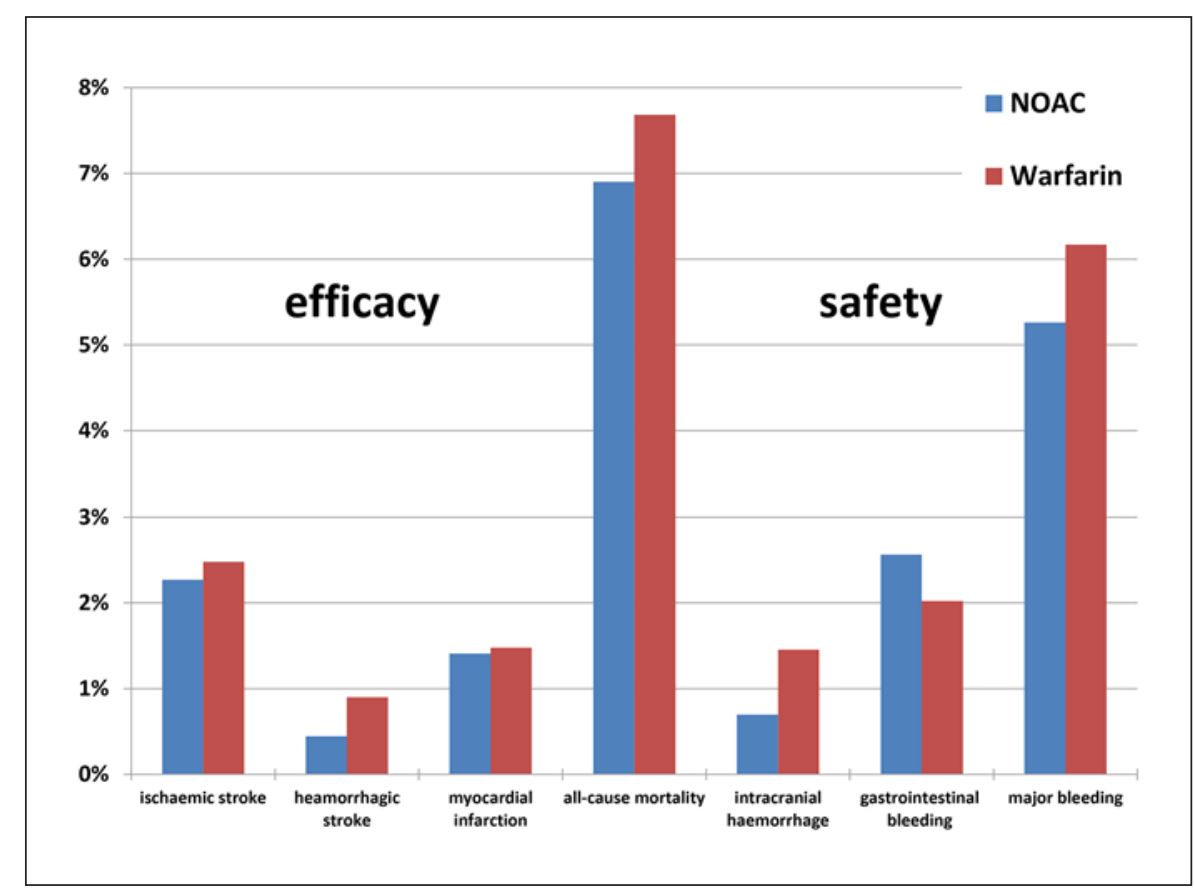

apy with VKA. Comments to this argue that the early stop of ASA after 4 weeks in $50 \%$ of the triple therapy cases plays a role.

In conclusion, due to lower bleeding rates and the lack of safety issues, DOAC instead of VKA is now recommended for AF patients undergoing stenting. The concept of dual therapy (DOAC and clopidogrel) is the treatment of choice in patients with AF and PCI. Until now, there is no clear recommendation on how long to extend ASA in these patients. Some data indicate that ASA given only periinterventionally might not be sufficient. In contrast, ASA for 4 weeks might be too long with regard to bleeding risk. Until more data are available, individual risk stratification is recommended. The complexity of PCI and the reason for initial presentation like ACS should favor prolonged initial ASA treatment. Bleeding rates are substantially reduced using the concept of dual therapy, but recurrent bleeding events may still occur in patients with very high bleeding risk. In these patients occlusion of the left atrial appendage is recommended [30].

\section{AF and Supraventricular Tachycardia}

Stroke prevention represents the main goal for $\mathrm{AF}$ treatment. Estimation of stroke risk in AF patients based on the $\mathrm{CHA}_{2} \mathrm{DS}_{2}$-VASc score is recommended [31]. In general, patients without clinical stroke risk factors do not need antithrombotic therapy, while patients with a $\mathrm{CHA}_{2} \mathrm{DS}_{2}$-VASc score of $\geq 1$ for men and $\geq 2$ for women are likely to benefit from oral anticoagulation, emphasiz- ing a relatively high and continuously increasing stroke risk for patients aged $\geq 65$ years [32,33] (Fig. 2). For AF patients with a $\mathrm{CHA}_{2} \mathrm{DS}_{2}$-VASc score $\geq 2$ there is a class I A recommendation for oral anticoagulation therapy (class IIa B for women with only one additional stroke risk factor). Bleeding scores, i.e., HAS-BLED [34], have been developed mostly on the basis of patients on VKA. As stroke and bleeding risk factors overlap, it is important to keep in mind that a high bleeding risk score should generally not result in withholding oral anticoagulation therapy. Rather, bleeding risk factors should be identified and treatable factors should be corrected [27].

Oral anticoagulants, but not aspirin, effectively prevent strokes in patients with $\mathrm{AF}$ [35]. Of note, the bleeding risk on aspirin is not different from the bleeding risk on VKA [36] or DOAC therapy [37]. In fact, VKA reduced the risk for stroke by two-thirds as well as the risk for death by one-quarter in comparison to aspirin or no antithrombotic medication. Accordingly, patients with atrial flutter (without AF) should be considered for anticoagulation, but the threshold for initiation is not established [38]. Taken together, when dose-adjusted to yield an adequate "time in therapeutic range," VKAs are considered safe and effective. On the other hand, the quality of international normalized ratio control by warfarin may not directly correspond with a reduction in intracranial hemorrhage events [39]. In contrast, DOACs do not require monitoring of coagulation. However, laboratory assessment of drug exposure and anticoagulant effect may help clinicians in emergencies such as bleeding, urgent procedures, suspected overdose, or acute stroke. How- 
ever, routine coagulation tests generally do not provide an accurate assessment of DOAC anticoagulant effects, and therefore these measurements should be performed in experienced laboratories [32].

Meanwhile, for patients with "nonvalvular" AF, DOACs emerged as the oral anticoagulant of first choice, especially when patients were newly started on anticoagulation. All four approved DOACs have been tested in AF patients against VKAs as comparator. A meta-analysis of these pivotal trials demonstrated that DOACs in high doses significantly reduced mortality by $10 \%$ and stroke or systemic embolic events by $19 \%$ compared to warfarin [40]. This effect was mainly driven by a reduction in hemorrhagic stroke of about $50 \%$. However, gastrointestinal bleeding events were increased by about $25 \%$.

The approved use of DOACs is limited to patients with adequate kidney function. Chronic kidney disease by itself increases the risk for both stroke and bleeding events in AF patients [41]. It seems that DOACs are superior to VKA in AF patients with mild to moderate chronic kidney disease in the prevention of strokes, systemic emboli, or major bleeding [42]. Until now, there is a lack of controlled trials on patients treated with DOACs with severe chronic kidney disease (GFR $<25-30 \mathrm{~mL} / \mathrm{min} / 1.73 \mathrm{~m}^{2}$ ) or hemodialysis patients treated with VKA [43]. A metaanalysis of 16 observational trials showed that oral anticoagulants were not associated with a reduced risk of thromboembolism in patients with AF on long-term dialysis. Warfarin, dabigatran, and rivaroxaban were associated with significantly higher bleeding risk compared with apixaban and no anticoagulant [44]. This reveals a need for further investigations because this group of patients shows even worse outcomes. In contrast, treatment with warfarin is reported to be safe in AF patients with moderate to severe chronic kidney disease up to a GFR of $\geq 15 \mathrm{~mL} / \mathrm{min} / 1.73 \mathrm{~m}^{2}$ [45]. The 2016 European guidelines on AF state that left atrial appendage occlusion may be considered for stroke prevention in patients with $\mathrm{AF}$ and contraindications for long-term anticoagulant treatment (e.g., those with a previous life-threatening bleed without a reversible cause) [27]. However, according to the lack of evidence, left atrial appendage occlusion in hemodialysis AF patients remains an object of discussion.

\section{Heart Failure}

There are no general recommendations for heart failure (HF) patients to be treated with an anticoagulant or antithrombocytic agent. The Guidelines for Anticoagulation in Heart Failure of the ESC date back to 2016 [46]. An expert consensus updated clinical practice on HF was published in 2019 [47], taking into account more recent studies with non-VKA oral anticoagulants (DOACs), es- pecially rivaroxaban. According to the consensus recommendation, the addition of a low dose of rivaroxaban of $2.5 \mathrm{mg}$ b.i.d. to a background treatment with aspirin may be considered for ambulatory, less symptomatic (NYHA I/II) patients with CCS and chronic heart failure and an ejection fraction $>30 \%$ in order to reduce the risk of cardiovascular death and stroke. However, in this context the addition of rivaroxaban is not recommended in chronic heart failure patients at higher risk, i.e., chronic heart failure patients with recent HF hospitalization or persistent NYHA III/IV symptoms. These recommendations are based on the findings of the COMMANDER-HF [48] and COMPASS trials [20]. The COMMANDER-HF trial randomized patients with $\mathrm{HF}$ and reduced ejection fraction, CAD (CCS), and recent HF hospitalizations with a background antiplatelet therapy to a low dose of rivaroxaban $2.5 \mathrm{mg}$ b.i.d. or placebo. The trial was found neutral on its primary endpoint, a composite of all-cause death, stroke, and acute myocardial infarction, as well as regarding bleeding leading to hospitalization or death. The larger COMPASS trial randomized stable patients with atherosclerotic disease (CCS/peripheral artery disease [PAD]) in a double-blind fashion to aspirin alone, rivaroxaban $2.5 \mathrm{mg}$ b.i.d. plus ASA, or rivaroxaban $5 \mathrm{mg}$ b.i.d. More than $20 \%$ of patients had HF (predominantly with left ventricular ejection fraction $\geq 40 \%$ ), but patients with NYHA III/IV symptoms and left ventricular ejection fraction $<30 \%$ were excluded. The trial was prematurely halted for "overwhelming" efficacy: the primary endpoint (myocardial infarction, stroke, and cardiovascular death) was significantly reduced in the low-dose rivaroxaban $2.5 \mathrm{mg}$ b.i.d. plus aspirin arm by $24 \%$ (compared to aspirin only). Of note, this effect was accompanied by an increase in major bleeding $(\mathrm{HR}=1.70)$, but there was no significant difference in intracranial or fatal bleeding. The relative effects observed were similar in patients with or without HF. In this cohort, the routine use of pantoprazole seemed safe and potentially helpful to reduce bleeding from gastroduodenal lesions, but not upper gastrointestinal events [49].

As patients with advanced HF often suffer from other comorbidities, especially AF, these AF patients should be treated with a DOAC in doses proved to be preventive for thromboembolic events. Therefore, in HF patients with AF the dual antithrombotic concept with a "vascular dose" of rivaroxaban $2.5 \mathrm{mg}$ b.i.d. plus aspirin should not be considered. The "vascular dose" may be considered in patients with atherosclerotic disease with no or mild HF as stated above. In patients with established $\mathrm{PAD}$, the COMPASS-PAD study [50] demonstrated a relevant reduction in major adverse limb events (1.5\% for rivaroxaban plus aspirin vs. $2.6 \%$ for aspirin alone), but again with a significant increase in major bleeding (3.0 vs. $2.0 \%$ ). Similar observations were reported from the recent VOY- 


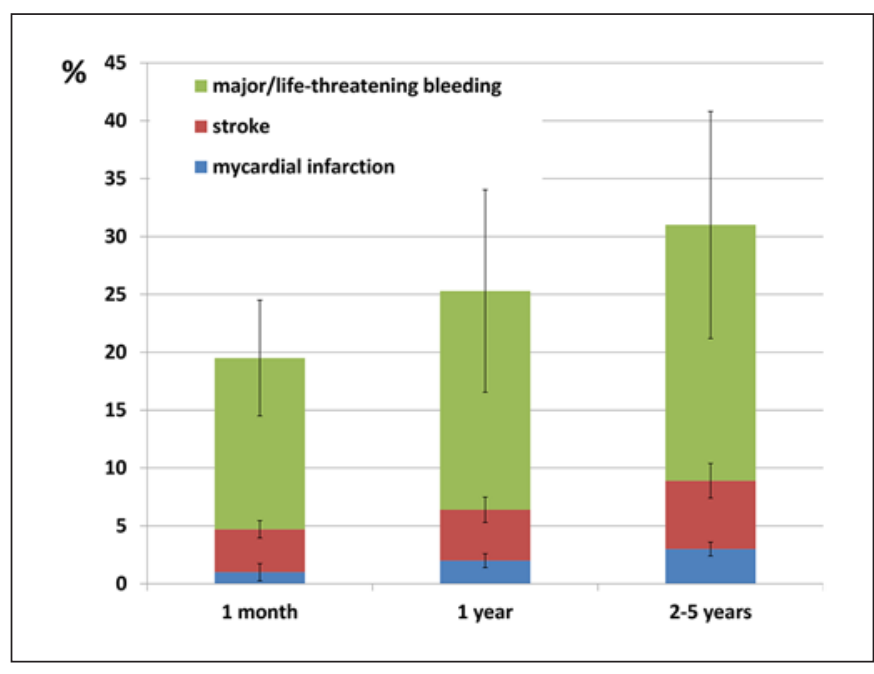

Fig. 3. Graphic summary of incidences of bleeding and ischemic complications according to time. Values are plotted as combined mean of event rates and standard error based on the incidences reported in large randomized controlled trials of intermediateand high-risk TAVI patients (modified from Anand et al. [50]). TAVI, transcatheter aortic valve implantation.

AGER PAD trial in patients with symptomatic PAD who had undergone lower extremity revascularization [51].

Taken together, the COMPASS trial showed that rivaroxaban plus aspirin was associated with fewer adverse cardiovascular events, but more major bleeding events versus aspirin alone. In patients at high risk for cardiovascular events, i.e., patients with CCS and PAD, the dual pathway approach may be of greater benefit. However, the risk of the composite net clinical benefit outcome of cardiovascular death, stroke, myocardial infarction, fatal bleeding, or symptomatic bleeding into a critical organ was lower with rivaroxaban plus aspirin than with aspirin alone $(4.7$ vs. $5.9 \%, \mathrm{HR}=0.80)$.

\section{Valvular Heart Disease}

In general, management of valvular heart disease per se does not require antithrombotic medication in the absence of other indications, i.e., AF. Of note, VKA, but not DOACs, is the only safe oral treatment option for the treatment of patients with "valvular" $\mathrm{AF}$, comprising (rheumatoid) mitral valve stenosis or mechanical valve prosthesis. Patients with "nonvalvular AF" may have other types of valvular heart disease (i.e., mitral insufficiency, aortic stenosis). One should emphasize that "nonvalvular AF" does not exclude patients with some types of valvular heart disease from therapy with DOAC. While patients with mechanical valve prostheses depend on a lifelong therapy with VKA [52], there is a growing number of pa- tients with surgically or interventionally implanted bioprostheses. For surgical bioprostheses, VKA should be considered during the first 3 months after surgical mitral or tricuspid valve implantation (or repair), but treatment with low-dose aspirin only in case of the aortic valve [46]. Interventional heart valve therapy, i.e., transcatheter aortic valve implantation (TAVI), meanwhile represents the principal treatment option in patients suffering from high-grade aortic stenosis. For TAVI procedures, DAPT (aspirin plus clopidogrel) for 3-6 months seems the treatment of choice, followed by lifelong single antiplatelet therapy. However, single antiplatelet therapy may be considered after TAVI in patients with high bleeding risk [46]. Due to the observation of early (partially subclinical) thrombosis of TAVI prostheses [53] there are ongoing attempts to test DOACs in this setting. However, findings of the prematurely halted GALILEO trial in post-TAVI patients showed that treatment with low-dose rivaroxaban $10 \mathrm{mg}$ once daily plus ASA was associated with a higher risk of death or thromboembolic complications as well as bleeding than a single antiplatelet-based strategy [54]. These findings led to a general safety alert for rivaroxaban in TAVI patients. Taken together, the larger randomized TAVI trials including patients with intermediate to high risk show that major and life-threatening bleeding exceeds by far the incidence of ischemic events like stroke or myocardial infarction over time (Fig. 3) [55].

In case of edge-to-edge repair for mitral valve regurgitation with the MitraClip ${ }^{\circledR}$ system the recommendations follow the postprocedural antithrombotic regimen of the first randomized EVEREST trial: patients with no other indication for anticoagulation should be treated with DAPT (DAPT with aspirin and clopidogrel) for 1 month followed by single aspirin up to 6 months at minimum. Patients on oral anticoagulation should be treated with 1 month of additional antiplatelet medication, but no triple therapy [56].

\section{Conclusion}

Antiaggregation and anticoagulation are key components of modern cardiology. Almost in all areas in cardiology these drugs are in use. The presented data show the benefits in terms of prognosis and adjunctive treatment in interventional cardiology. However, careful judgement of the inherent bleeding risk in the single patient is of paramount importance.

\section{Conflict of Interest Statement}

The authors have no conflicts of interest to declare. 


\section{Funding Sources}

There are no funding sources.

\section{Author Contributions}

Both authors contributed equally to the content of this review.

\section{References}

1 Hearnshaw SA, Logan RF, Lowe D, Travis SP, Murphy MF, Palmer KR. Acute upper gastrointestinal bleeding in the UK: patient characteristics, diagnoses and outcomes in the 2007 UK audit. Gut. 2011 Oct;60(10):1327-35.

2 Mehran R, Rao SV, Bhatt DL, Gibson CM, Caixeta A, Eikelboom J, et al. Standardized bleeding definitions for cardiovascular clinical trials: a consensus report from the Bleeding Academic Research Consortium. Circulation. 2011 Jun;123(23):2736-47.

3 Urban P, Mehran R, Colleran R, Angiolillo DJ, Byrne RA, Capodanno D, et al. Defining high bleeding risk in patients undergoing percutaneous coronary intervention: a consensus document from the Academic Research Consortium for High Bleeding Risk. Eur Heart J. 2019 Aug;40(31):2632-53.

4 Townsend N, Nichols M, Scarborough P, Rayner M. Cardiovascular disease in Europe - epidemiological update 2015. Eur Heart J. 2015 Oct;36(40):2696-705

5 Townsend N, Wilson L, Bhatnagar P, Wickramasinghe K, Rayner M, Nichols M. Cardiovascular disease in Europe: epidemiological update 2016. Eur Heart J. 2016 Nov;37(42): 3232-45.

6 Knuuti J, Wijns W, Saraste A, Capodanno D, Barbato E, Funck-Brentano C, et al. 2019 ESC guidelines for the diagnosis and management of chronic coronary syndromes. Eur Heart J. 2020 Jan;41(3):407-77.

7 Valgimigli M, Bueno H, Byrne RA, Collet JP, Costa F, Jeppsson A, et al. 2017 ESC Focused Update on Dual Antiplatelet Therapy in Coronary Artery Disease Developed in Collaboration With EACTS: The Task Force for Dual Antiplatelet Therapy in Coronary Artery Disease of the European Society of Cardiology (ESC) and of the European Association for Cardio-Thoracic Surgery (EACTS). Eur Heart J. 2018 Jan;39(3):213-60.

8 Yusuf S, Zhao F, Mehta SR, Chrolavicius S, Tognoni G, Fox KK; Clopidogrel in Unstable Angina to Prevent Recurrent Events Trial Investigators. Effects of clopidogrel in addition to aspirin in patients with acute coronary syndromes without ST-segment elevation. N Engl J Med. 2001 Aug;345(7):494-502.

9 Wallentin L, Becker RC, Budaj A, Cannon CP, Emanuelsson $\mathrm{H}$, Held C, et al. Ticagrelor versus clopidogrel in patients with acute coronary syndromes. N Engl J Med. 2009 Sep; 361(11):1045-57.

10 James SK, Roe MT, Cannon CP, Cornel JH, Horrow J, Husted S, et al.; PLATO Study Group. Ticagrelor versus clopidogrel in patients with acute coronary syndromes intended for non-invasive management: substudy from prospective randomised PLATelet inhibition and patient Outcomes (PLATO) trial. BMJ. 2011 Jun;342:d3527.

11 Costa F, van Klaveren D, James S, Heg D, Räber L, Feres F, et al.; PRECISE-DAPT Study
Investigators. Derivation and validation of the predicting bleeding complications in patients undergoing stent implantation and subsequent dual antiplatelet therapy (PRECISE-DAPT) score: a pooled analysis of individual-patient datasets from clinical trials. Lancet. 2017 Mar;389(10073):1025-34.

12 Chen X, Barywani SB, Sigurjonsdottir R, Fu $M$. Improved short and long term survival associated with percutaneous coronary intervention in the elderly patients with acute coronary syndrome. BMC Geriatr. 2018 Jun; 18(1):137.

13 Schüpke S, Neumann FJ, Menichelli M, Mayer K, Bernlochner I, Wöhrle J, et al.; ISARREACT 5 Trial Investigators. Ticagrelor or Prasugrel in Patients with Acute Coronary Syndromes. N Engl J Med. 2019 Oct;381(16): 1524-34.

14 Mehran R, Baber U, Sharma SK, Cohen DJ, Angiolillo DJ, Briguori C, et al. Ticagrelor with or without aspirin in high-risk patients after PCI. N Engl J Med. 2019 Nov;381(21): 2032-42.

15 Bowman L, Mafham M, Wallendszus K, Stevens W, Buck G, Barton J, et al. Effects of aspirin for primary prevention in persons with diabetes mellitus. N Engl J Med. 2018 Oct; 379(16):1529-39.

16 Maron DJ, Hochman JS, Reynolds HR, Bangalore S, O'Brien SM, Boden WE, et al.; ISCHEMIA Research Group. Initial Invasive or Conservative Strategy for Stable Coronary Disease. N Engl J Med. 2020 Apr;382(15): 1395-407.

17 Gori T, Polimeni A, Indolfi C, Räber L, Adriaenssens T, Münzel T. Predictors of stent thrombosis and their implications for clinical practice. Nat Rev Cardiol. 2019 Apr;16(4): 243-56.

18 Baigent C, Blackwell L, Collins R, Emberson J, Godwin J, Peto R, et al.; Antithrombotic Trialists' (ATT) Collaboration. Aspirin in the primary and secondary prevention of vascular disease: collaborative meta-analysis of individual participant data from randomised trials. Lancet. 2009 May;373(9678): 1849-60.

19 Bonaca MP, Bhatt DL, Cohen M, Steg PG, Storey RF, Jensen EC, et al.; PEGASUS-TIMI 54 Steering Committee and Investigators. Long-term use of ticagrelor in patients with prior myocardial infarction. N Engl J Med. 2015 May;372(19):1791-800.

20 Eikelboom JW, Connolly SJ, Bosch J, Dagenais GR, Hart RG, Shestakovska O, et al.; COMPASS Investigators. Rivaroxaban with or without Aspirin in Stable Cardiovascular Disease. N Engl J Med. 2017 Oct;377(14): 1319-30.

21 Palmerini T, Della Riva D, Benedetto U, Bacchi Reggiani L, Feres F, Abizaid A, et al. Three, six, or twelve months of dual antiplatelet therapy after DES implantation in patients with or without acute coronary syndromes: an individual patient data pairwise and network meta-analysis of six randomized trials and 11473 patients. Eur Heart J. 2017 Apr;38(14): 1034-43.

22 Watanabe H, Domei T, Morimoto T, Natsuaki M, Shiomi H, Toyota T, et al.; STOPDAPT-2 Investigators. Effect of 1-Month Dual Antiplatelet Therapy Followed by Clopidogrel vs 12-Month Dual Antiplatelet Therapy on Cardiovascular and Bleeding Events in Patients Receiving PCI: The STOPDAPT-2 Randomized Clinical Trial. JAMA. 2019 Jun; 321(24):2414-27.

23 Windecker S, Latib A, Kedhi E, Kirtane AJ, Kandzari DE, Mehran R, et al.; ONYX ONE Investigators. Polymer-based or Polymer-free Stents in Patients at High Bleeding Risk. N Engl J Med. 2020 Mar;382(13):1208-18.

24 Morita Y, Hamaguchi T, Yamaji Y, Hayashi H, Nakane E, Haruna Y, et al. Temporal trends in prevalence and outcomes of atrial fibrillation in patients undergoing percutaneous coronary intervention. Clin Cardiol. 2020 Jan;43(1):33-42.

25 Dewilde WJ, Oirbans T, Verheugt FW, Kelder JC, De Smet BJ, Herrman JP, et al.; WOEST study investigators. Use of clopidogrel with or without aspirin in patients taking oral anticoagulant therapy and undergoing percutaneous coronary intervention: an open-label, randomised, controlled trial. Lancet. 2013 Mar;381(9872):1107-15.

26 Gibson CM, Mehran R, Bode C, Halperin J, Verheugt FW, Wildgoose $\mathrm{P}$, et al. Prevention of bleeding in patients with atrial fibrillation undergoing PCI. N Engl J Med. 2016 Dec; 375(25):2423-34.

27 Cannon CP, Bhatt DL, Oldgren J, Lip GY, Ellis SG, Kimura T, et al.; RE-DUAL PCI Steering Committee and Investigators. Dual antithrombotic therapy with dabigatran after PCI in atrial fibrillation. N Engl J Med. 2017 Oct; 377(16):1513-24.

28 Lopes RD, Heizer G, Aronson R, Vora AN, Massaro T, Mehran R, et al.; AUGUSTUS Investigators. Antithrombotic therapy after acute coronary syndrome or PCI in atrial fibrillation. N Engl J Med. 2019 Apr;380(16): 1509-24.

29 Vranckx P, Valgimigli M, Eckardt L, Tijssen J, Lewalter T, Gargiulo G, et al. Edoxabanbased versus vitamin $\mathrm{K}$ antagonist-based antithrombotic regimen after successful coronary stenting in patients with atrial fibrillation (ENTRUST-AF PCI): a randomised, open-label, phase 3b trial. Lancet. 2019 Oct; 394(10206):1335-43.

30 Glikson M, Wolff R, Hindricks G, Mandrola J, Camm AJ, Lip GYH, et al. EHRA/EAPCI expert consensus statement on catheterbased left atrial appendage occlusion - an update. Europace. 2019 doi: 10.1093/europace/ euz258 [Epub ahead of print]. 
31 Lip GY. Stroke and bleeding risk assessment in atrial fibrillation: when, how, and why? Eur Heart J. 2013 Apr;34(14):1041-9.

32 Kirchhof P, Benussi S, Kotecha D, Ahlsson A, Atar D, Casadei B, et al.; ESC Scientific Document Group. 2016 ESC Guidelines for the management of atrial fibrillation developed in collaboration with EACTS. Eur Heart J. 2016 Oct;37(38):2893-962.

33 Fauchier L, Clementy N, Bisson A, Ivanes F, Angoulvant D, Babuty D, et al. Should Atrial Fibrillation Patients With Only 1 NongenderRelated CHA2DS2-VASc Risk Factor Be Anticoagulated? Stroke. 2016 Jul;47(7):1831-6.

34 Pisters R, Lane DA, Nieuwlaat R, de Vos CB, Crijns HJ, Lip GY. A novel user-friendly score (HAS-BLED) to assess 1-year risk of major bleeding in patients with atrial fibrillation: the Euro Heart Survey. Chest. 2010 Nov;138(5): 1093-100.

35 Hart RG, Pearce LA, Aguilar MI. Meta-analysis: antithrombotic therapy to prevent stroke in patients who have nonvalvular atrial fibrillation. Ann Intern Med. 2007 Jun;146(12): 857-67.

36 Mant J, Hobbs FD, Fletcher K, Roalfe A Fitzmaurice D, Lip GY, et al.; BAFTA investigators; Midland Research Practices Network (MidReC). Warfarin versus aspirin for stroke prevention in an elderly community population with atrial fibrillation (the Birmingham Atrial Fibrillation Treatment of the Aged Study, BAFTA): a randomised controlled trial. Lancet. 2007 Aug;370(9586):493-503.

37 Steffel J, Verhamme P, Potpara TS, Albaladejo P, Antz M, Desteghe L, et al.; ESC Scientific Document Group. The 2018 European Heart Rhythm Association Practical Guide on the use of non-vitamin $\mathrm{K}$ antagonist oral anticoagulants in patients with atrial fibrillation: executive summary. Europace. 2018 Aug; 20(8):1231-42.

38 Vadmann H, Nielsen PB, Hjortshøj SP, Riahi S, Rasmussen LH, Lip GY, et al. Atrial flutter and thromboembolic risk: a systematic review. Heart. 2015 Sep;101(18):1446-55.

39 Wallentin L, Yusuf S, Ezekowitz MD, Alings M, Flather M, Franzosi MG, et al.; RE-LY investigators. Efficacy and safety of dabigatran compared with warfarin at different levels of international normalised ratio control for stroke prevention in atrial fibrillation: an analysis of the RE-LY trial. Lancet. 2010 Sep; 376(9745):975-83.
40 Ruff CT, Giugliano RP, Braunwald E, Hoffman EB, Deenadayalu N, Ezekowitz MD, et al. Comparison of the efficacy and safety of new oral anticoagulants with warfarin in patients with atrial fibrillation: a meta-analysis of randomised trials. Lancet. 2014 Mar;383(9921): 955-62.

41 Olesen JB, Lip GY, Kamper AL, Hommel K, Køber L, Lane DA, et al. Stroke and bleeding in atrial fibrillation with chronic kidney disease. N Engl J Med. 2012 Aug;367(7):625-35.

42 Del-Carpio Munoz F, Yao X, Abraham NS, Bellolio MF, Rabinstein AA, Asirvatham SJ, et al. Dabigatran Versus Warfarin in Relation to Renal Function in Patients With Atrial Fibrillation. J Am Coll Cardiol. 2016 Jul;68(1):12931.

43 Marinigh R, Lane DA, Lip GY. Severe renal impairment and stroke prevention in atrial fibrillation: implications for thromboprophylaxis and bleeding risk. J Am Coll Cardiol. 2011 Mar;57(12):1339-48.

44 Kuno T, Takagi H, Ando T, Sugiyama T, Miyashita S, Valentin N, et al. Oral Anticoagulation for Patients With Atrial Fibrillation on Long-Term Hemodialysis. J Am Coll Cardiol. 2020 Jan;75(3):273-85.

45 Hart RG, Pearce LA, Asinger RW, Herzog CA. Warfarin in atrial fibrillation patients with moderate chronic kidney disease. Clin J Am Soc Nephrol. 2011 Nov;6(11):2599-604.

46 Ponikowski P, Voors AA, Anker SD, Bueno H, Cleland JG, Coats AJ, et al.; Authors/Task Force Members; Document Reviewers. 2016 ESC Guidelines for the diagnosis and treatment of acute and chronic heart failure: the Task Force for the diagnosis and treatment of acute and chronic heart failure of the European Society of Cardiology (ESC). Developed with the special contribution of the Heart Failure Association (HFA) of the ESC. Eur J Heart Fail. 2016 Aug;18(8):891-975.

47 Seferovic PM, Ponikowski P, Anker SD, Bauersachs J, Chioncel O, Cleland JG, et al. Clinical practice update on heart failure 2019: pharmacotherapy, procedures, devices and patient management. An expert consensus meeting report of the Heart Failure Association of the European Society of Cardiology. Eur J Heart Fail. 2019 Oct;21(10):1169-86.
48 Greenberg B, Neaton JD, Anker SD, Byra WM, Cleland JG, Deng H, et al. Association of Rivaroxaban With Thromboembolic Events in Patients With Heart Failure, Coronary Disease, and Sinus Rhythm: A Post Hoc Analysis of the COMMANDER HF Trial. JAMA Cardiol. 2019 Jun;4(6):515-23.

49 Moayyedi P, Eikelboom JW, Bosch J, Connolly SJ, Dyal L, Shestakovska O, et al.; COMPASS Investigators. Pantoprazole to Prevent Gastroduodenal Events in Patients Receiving Rivaroxaban and/or Aspirin in a Randomized, Double-Blind, Placebo-Controlled Trial. Gastroenterology. 2019 Aug;157(2):403412.e5.

50 Anand SS, Caron F, Eikelboom JW, Bosch J, Dyal L, Aboyans V, et al. Major Adverse Limb Events and Mortality in Patients With Peripheral Artery Disease: the COMPASS Trial. J Am Coll Cardiol. 2018 May;71(20):2306-15.

51 Bonaca MP, Bauersachs RM, Anand SS, Debus ES, Nehler MR, Patel MR, et al. Rivaroxaban in Peripheral Artery Disease after Revascularization. N Engl J Med. 2020 May;382(21): 1994-2004.

52 Baumgartner H, Falk V, Bax JJ, De Bonis M, Hamm C, Holm PJ, et al.; ESC Scientific Document Group. 2017 ESC/EACTS Guidelines for the management of valvular heart disease. Eur Heart J. 2017 Sep;38(36):2739-91.

53 Chakravarty T, Søndergaard L, Friedman J, De Backer O, Berman D, Kofoed KF, et al.; RESOLVE; SAVORY Investigators. Subclinical leaflet thrombosis in surgical and transcatheter bioprosthetic aortic valves: an observational study. Lancet. 2017 Jun;389(10087): 2383-92.

54 Dangas GD, Tijssen JG, Wöhrle J, Søndergaard L, Gilard M, Möllmann H, et al.; GALILEO Investigators. A Controlled Trial of Rivaroxaban after Transcatheter Aortic-Valve Replacement. N Engl J Med. 2020 Jan;382(2): 120-9.

55 Nijenhuis VJ, Brouwer J, Søndergaard L, Collet JP, Grove EL, Ten Berg JM. Antithrombotic therapy in patients undergoing transcatheter aortic valve implantation. Heart. 2019 May; 105(10):742-8.

56 Boekstegers P, Hausleiter J, Baldus S, von Bardeleben RS, Beucher H, Butter C, et al. Percutaneous interventional mitral regurgitation treatment using the MitraClip system. Clin Res Cardiol. 2014 Feb;103(2):85-96. 